\title{
A Governança Territorial no Circuito das Malhas do Sul de Minas Gerais
}

The Territorial Governance in the Circuit of the Meshes of Minas Gerais South Le Gouvernement Territorial dans le Circuit des Mailles du Sud de Minas Gerais

El Gobierno Territorial en el Circuito de las Mallas del Sur de Minas Gerais

\author{
Lucas Labigalini Fuini*
}

Recebido em 10/2/2008; revisado e aprovado em 23/5/2008; aceito em 13/7/2008.

\begin{abstract}
Resumo: Este trabalho tem como objetivo central caracterizar a importância de estruturas de coordenação e regulação locais na dinâmica territorial do "Circuito das Malhas do Sul de Minas Gerais", agregando-se um novo elemento ao estudo da competitividade territorial: a consideração das formas de "governança" e distribuição de poder em cadeias e sistemas produtivos com forte componente local e regional.

Palavras-chave : Governança. Território. Circuito das malhas.

Abstract: This work has as central objective to characterize the importance of local coordination and regulation structures in the territorial dynamics of "Circuit of the Meshes of Minas Gerais South", adding a new element to the study of the territorial competitiveness: the consideration of the "governance" and distribution of power forms in chains and productive systems with local and regional component fort.

Key words: Governance. Territory. Circuit of the meshes.

Résumé: Ce travail a comme objectif central caractériser l'importance de structures de coordination et le règlement locale dans la dynamique territoriale dans le «Circuit des Mailles du Sud de Minas Gerais », en s'ajoutant un nouvel élément à l'étude de la compétitivité territoriale: la considération des formes de « gouvernement » et la distribution de pouvoir dans des chaînes et des systèmes productifs avec fort composant local et régional.

Mots-clé: Gouvernement. Territoire. Circuit des mailles.

Resumen: Este trabajo tiene como objetivo central caracterizar la importancia de estructuras de coordinación y el Reglamento local en la dinámica territorial en el "Circuito de las Mallas del Sur de Minas Gerais", en s' añadiendo un nuevo elemento a l' estudio de la competitividad territorial: la consideración de las formas de "Gobierno" y la distribución de poder en cadenas y sistemas productivos con muy componente local y regional.

Palabras clave : Gobierno. Território. Circuito de las mallas.
\end{abstract}

\section{Introdução}

O presente artigo tem como objetivo central caracterizar a importância de estruturas de coordenação e regulação locais na dinâmica territorial de vantagens competitivas, agregando-se um novo elemento ao estudo da competitividade territorial: as formas de "governança" e distribuição de poder em cadeias e sistemas produtivos com forte componente local e regional. Trata-se de um estudo teórico e empírico extraído de idéias contidas na Dissertação de Mestrado intitulada "A Relação entre Território e Competitividade no Circuito das Malhas do Sul de Minas Gerais", defendida pelo autor deste artigo no início de 2006.

Deste modo, a noção de governança vai além de uma simples forma de organização inter-empresarial concebida por relações puramente mercantis, associando-se também às modalidades de coordenação econômicas mais complexas que abarcam instituições, convenções, registros de ação e formas de incerteza, definindo, assim, um tipo de regulação misto entre o político e o econômico, entre o local e o nacional, com forte conteúdo territorial. Pode-se trabalhar, então, com a idéia de uma "governança territorial" posto que o complexo de relações entre atores e instituições define novas formas de regulação e coordenação de arranjos produtivos em âmbito local e regional. Associado ao termo governança, emerge também um quadro conceitual que envolve termos como "cooperação", "capital social" e "recursos específicos". A definição destes conceitos e sua associação ao temário mais geral da "governança" é também uma das demandas atuais quanto à realização de reflexões teóricas e empíricas que dêem conta da complexidade das relações sócio-produtivas e das novas

\footnotetext{
* Professor das Faculdades Asmec/MG e Mestre em Geografia pela Unesp-Rio Claro. É atualmente Doutorando pelo Programa de Pós-graduação em Geografia da Unesp-Rio Claro comfinanciamento pela FAPESP. Rua 10, 2527, Rio Claro/SP; tel.: (19) 3863-3593. E-mail: lucasfuini@yahoo.com.br.
} 
formas de organização espacial da indústria.

$\mathrm{O}$ artigo organiza-se em três partes centrais: na primeira define-se o conteúdo do termo "governança" e sua associação com a categoria "território". Na segunda buscase aprofundar o quatro teórico da governança com a exploração de alguns conceitos próximos. $\mathrm{Na}$ terceira esboça-se o quadro empírico das relações institucionais e regulatórias do "Circuito das Malhas do Sul de Minas Gerais".

\section{Os Aspectos teórico-conceituais da Governança Territorial}

Em torno do debate atualmente realizado sobre a importância de estruturas de coordenação e regulação locais na dinamização territorial de vantagens competitivas e promoção do desenvolvimento territorial, agrega-se mais um elemento ao estudo da competitividade dos territórios: as formas de "governança" ou de distribuição de poder em cadeias e sistemas produtivos.

A governança se refere às estruturas de coordenação e tomada de decisões na rede de relações entre unidades de produção e fornecedores-compradores, envolvendo a combinação de diferentes formas de hierarquia, subcontratação, parceria, "atmosfera", agências públicas e para-públicas, de cooperação em tecnologias, etc. (BENKO, 1996). Tais formas de coordenação e organização do território tendem a se fortalecer com a redefinição do papel do Estado e sua crescente descentralização político-administrativa, potencializando o papel do local como âmbito do desenvolvimento territorial.

Essa noção ganha destaque com a maior flexibilização dos sistemas produtivos pós-fordistas, que fazem proliferar uma série de organizações em rede, relações contratuais e parcerias informais. Desse modo, a governança vai além de uma simples forma de organização inter-empresarial - concebida, sobretudo, por relações mercantis - passando a caracterizar modalidades de coordenação econômica mais complexas que abarcam instituições, convenções, registros de ação e formas de incerteza, definindo, assim, um tipo de regulação misto entre a política e economia, eminentemente locais. Pode ainda estar associada a uma estrutura composta por diferentes atores e instituições que permitem apreciar as regras e rotinas que fazem a especificidade de um lugar vis a vis a outros lugares no sistema produtivo nacional, revelando as capacidades locais de adaptação a lógica dos ramos e processos de aprendizagem (CORROLLEUR, 1994 apud PIRES, 2003).

A governança territorial interfere na competitividade das regiões ao definir formas de distribuição de poder em cadeias produtivas e outras formas de relacionamento comercial, institucional e industrial, fazendo convergir, em torno de um ator central, uma grande empresa, ou compartilhando, em vários atores articulados por uma instância coletiva, a tarefa de definir as estratégias competitivas principais de um aglomerado produtivo local.

A importância da governança local como uma fonte de competitividade tem sido particularmente enfatizada em duas linhas recentes de trabalho: ciência regional (e em particular a literatura do distrito industrial); e estudos de inovação. Estes dois corpos de trabalho consideram ambos a insuficiência da dinâmica do mercado para chegar à competitividade via high road, p. ex., através do upgrading. Na literatura do distrito industrial, a experiência da "Terceira Itália" e outras experiências européias dão forças (no final dos anos 1980 e início dos 90) para um novo modelo de política industrial local/ regional que: (1) ênfase na delegação de funções para uma diversa gama de instituições governamentais e não governamentais; (2) opera através de instituições associadas a livre iniciativa, (3) estende a associação do empreendedorismo do setor privado para o público e (4) destaca a auto-ajuda (auxílio mútuo) através de associações de negócios e consórcio de produtores. (. Em outras palavras, a proposição é que o desenvolvimento e a rápida difusão de conhecimento dentro do cluster não é somente resultado de sinergias acidentais, a "atmosfera industri$\mathrm{al}^{\prime \prime}$, mas são buscados por redes políticas de atores públicos e privados.. Isto contribui para uma nova ênfase sobre a Região como nexo do aprendizado e efeitos de inovação. (HUMPHREY; SCHIMTZ, 2002, p. 1019).

Essas estratégias podem, então, basearse em investimentos na capacitação da mãode-obra e na inovação, qualificação dos recursos e especificação, ou podem estar assentadas na redução de contingente e pagamen- 
to de salários baixos, tirando seu diferencial concorrencial no jogo de preços do mercado. A governança é, pois, um elo essencial que liga a empresa a seus fornecedores, compradores e parceiros, públicos e privados.

Castro (2003) salienta que a densidade institucional inscrita nos territórios tem influência decisiva no desempenho econômico dos lugares, por meio de seus sistemas produtivos, e no campo da regulação política do espaço, aparecendo como instrumentos cuja territorialização indica o exercício da cidadania através do vínculo entre distribuição espacial e posse efetiva de direitos. Desse modo, o arcabouço normativo-institucional acoplado à concepção de governança é elemento indispensável para o diagnóstico do "desenvolvimento" da "competitividade" territorial. Boyer (1990, p. 73) caracteriza como formas institucionais "toda codificação de uma ou várias relações sociais fundamentais, resultando tais formas sociais do tipo de caracterização que se faz do modo de produção dominante", destacando o espaço nacional como ambiente principal da regulação. As principais instituições, ou formas institucionais, presentes no regime de capitalista, seriam: a) as formas de restrição monetária (envolve a gestão monetária e as políticas de preços e câmbio); b) as configurações da relação salarial (tipos de organização do trabalho e modalidades de reprodução dos assalariados); c) formas de concorrência (relação entre estágios concorrenciais e monopolistas e controle estatal); d) modalidades de adesão ao regime internacional (adesão às regras que definem as relações entre Estados-nação) e, e) as formas de Estado (conjunto de compromissos institucionalizados que define a integração do Estado ao regime de acumulação).

\section{Os Conceitos correlatos à Governança Territorial}

A "cooperação" é um outro componente do sistema de valores compartilhados localmente e que caracteriza, no âmbito da concorrência e da competitividade, uma busca por aperfeiçoamento tecnológico e produtivo que não é regulada somente por custos e preços, incluindo a possibilidade de distribuir os riscos e benefícios de um "siste- ma produtivo localizado" a partir das múltiplas formas de interação das empresas com as instituições e poderes locais dentro de um projeto coletivo. Cooperar neste sentido é dividir riscos, compartilhar incertezas e distribuir custos, alavancando o potencial competitivo de muitas empresas cujo capital restrito, às vezes, impede o acesso a determinados equipamentos e produtos tecnológicos. Bons exemplos dessas formas de organizações cooperativas são os próprios APLs, que representam umas das possibilidades de desenvolver benefícios mútuos e sinergias positivas. Cooperar também está associado, desse modo, a formas mais horizontais de relacionamento e reciprocidade, que Santos (1996) conceitua como acontecer solidário e contigüidade, estimulando projetos de desenvolvimento regional-local pautados em uma maior autonomia política e social não dissociada do aperfeiçoamento da produtividade econômica.

As aglomerações de indústrias especializadas funcionam como o meio geográfico onde os pequenos produtores em uma divisão social do trabalho (estabelecimentos especializados em diferentes atividades complementares) realizam as economias externas de escala, ou seja, o crescimento e as vantagens competitivas desses sistemas industriais localizados são geralmente baseados em um suporte mais ou menos amplo de instituições, atividades e serviços em elos sinérgicos, suporte este que pode estar concentrado em associações comerciais, por exemplo. As associações comerciais e industriais têm o importante papel de institucionalizar os elos do aglomerado, favorecendo a competitividade da economia regional como um todo.

Além de proporcionar um foro neutro para a identificação de necessidades, limitações e oportunidades comuns, as associações têm condições de atuar em pontos focais para a abordagem dessas questões. As associações geralmente assumem a iniciativa na organização de feiras e delegações nacionais e internacionais, desenvolvem programas de treinamento, em conjunto com as instituições locais, gerenciam consórcios de compradores, implementam atividades de pesquisa e instalações de testes, com base em universidades; coletam informações relacionadas com o aglomerado; proporcionam um 
ambiente adequado para a discussão de problemas gerenciais comuns e se dedicam a muitas outras questões de interesse comum. Essas atividades se adicionam às funções tradicionais de atuar como interface com os governos locais, estaduais e centrais, orientando as reformas nos regulamentos e representando o aglomerado junto a outros grupos empresariais. (PORTER, 1999, p. 102).

Outras instituições que podem fortalecer o vínculo cooperativo entre os atores locais são os estabelecimentos de ensino que ministram disciplinas úteis à localidade, as joint-ventures e alianças estratégicas entre empresas, agências governamentais e paragovernamentais e o próprio poder público municipal ou estadual. Desse modo, a competitividade de pequenas e médias empresas acaba sendo fortemente dependente do meio onde estão inseridas, salientando os elos cooperativos que as empresas estabelecem com os demais elementos do território. As relações de cooperação envoltas na forma de convenções e de governança têm se respaldado em comunidades sociais cujos valores baseiam-se no apoio mútuo, denominado de capital social, objetivo bastante difundido atualmente no processo de construção de formas de regulação dos sistemas produtivos.

O capital social, segundo Putnam (2000, p. 177 apud VALENTIM, 1999), diz respeito às características da organização social como confiança, normas, organização, instituições e sistemas, que contribuam para aumentar a eficiência da sociedade, facilitando as ações coordenadas. Trata-se, pois de um conjunto de elementos que fazem parte da estrutura social e da cultura, como, por exemplo, as normas de reciprocidade, os padrões de associativismo, os hábitos de confiança entre as pessoas, as redes que ligam segmentos variados da comunidade. A influência do capital acumulado em práticas sociais sobre a produtividade e competitividade econômica tem relação com as práticas colaborativas entre indústrias e destas com universidades e entidades governamentais e da sociedade civil que impulsionam inovações viabilizando o dinamismo econômico de pequenas e médias empresas que alavancam a renda e o emprego local.

Benko; Pecqueur (2001) caracterizam o conjunto de fatores não necessariamente mercantis e eminentemente sociais e cultu- rais que estimulam a diferenciação dos territórios, pela tipologia dos recursos e ativos, genéricos e específicos. Os recursos são fatores ainda latentes, a organizar e explorar e os ativos são fatores já em mobilização. Os ativos e recursos genéricos são fatores totalmente transferíveis, espacialmente através de trocas mercantis, caracterizando seu valor no processo produtivo por uma questão de preço, como nos moldes da antiga idéia de competitividade industrial. Já os ativos e recursos específicos implicam em custos de transferência muito elevados ou que não podem ser dimensionados, definindo seu valor em função das condições de seu uso e dos processos interativos e cognitivos engendrados no ambiente histórico-cultural em que são configurados. Estes últimos elementos são aqueles que definem a diferenciação de um contexto territorial na concorrência com outros lugares através dos serviços e fornecedores especializados, da mão-de-obra qualificada e, sobretudo, das estruturas organizacionais e institucionais locais (COLLETIS-WAHL; PECQUEUR, 2001).

As estruturas de governança territorial, quando ancoradas em projetos para resolução de problemas associadas aos aglomerados produtivos e seu entorno, funcionam também como recursos e ativos específicos, visto que a complexidade das relações de conhecimento, cooperação e poder não podem ser transferidas entre contextos territoriais distintos.

Ao se exporem os principais elementos que fazem da competitividade uma noção mais ampla e complexa, face aos processos econômicos contemporâneos caracterizados pela mudança nas formas de organização das empresas em redes com maior ênfase à inovação e ao aprendizado tecnológico, fica patente que o território - em sua condição de configuração espacial de processos econômicos, políticos e sociais - adquire grande proeminência nos processos econômicos atuais. Trata-se de um "retorno" ao território como elemento essencial do desenvolvimento econômico, através de contextos locais bem-sucedidos na promoção de suas atividades econômicas, em uma densidade de atores e instituições reguladoras que possibilitam a criação de interdependências positivas e recursos específicos. 


\section{A Caracterização da Governança Territorial do Circuito das Malhas do Sul de Minas Gerais}

A região compreendida pelo "Circuito das Malhas do Sul de Minas Gerais" abarca um conjunto de seis pequenos municípios localizados no extremo sudoeste do Estado de Minas (Monte Sião, Jacutinga, Ouro Fino, Borda da Mata, Bueno Brandão e Inconfidentes), na divisa com o extremo leste do Estado de São Paulo, compartilhando da mesma paisagem montanhosa (Serra da Mantiqueira) e recebendo a influência da polarização econômica do eixo São Paulo-Campinas, principal mercado consumidor da atividade turística e industrial local.

O "Circuito Turístico das Malhas do Sul de Minas" é resultado de uma política formal de desenvolvimento regional iniciada pela Secretaria de Turismo do Estado de Minas Gerais, que visa conceder certificação e incentivos a uma série de circuitos turísticos espalhados pelo território estadual. É definição contida no Decreto Lei 43.321, assinado pelo Governador do Estado de Minas Gerais Aécio Neves em 08 de junho de 2003, que institucionalizou os Circuitos Turísticos. Um circuito é formado pela reunião de dois ou mais municípios em torno de uma atividade econômica principal e, por esse princípio, Jacutinga, Monte Sião e mais quatro municípios vizinhos se articulam em torno da produção de artigos de malha.

Esse órgão teve como medida inicial para sua oficialização a formação de uma Associação que integra representantes das Associações Comerciais e Industriais e Prefeituras dos seis municípios integrantes. $\mathrm{O}$ segundo passo foi a elaboração de um Plano de Desenvolvimento Turístico que garantiu o recebimento de um certificado provisório pela Secretaria de Turismo do Estado, em cerimônia realizada em março de 2006.

Nesse contexto, destacam-se os municípios mineiros de Jacutinga e Monte Sião, dois dos principais centros produtores de artigos em malha do Brasil - centros altamente especializados no segmento industrial de malharias e confecções de artigos do Vestuário. Segundo dados da RAIS (2003), em Monte Sião se localizam mais de $26 \%$ dos estabelecimentos de produção têxtil de Minas
Gerais, seguido por Jacutinga, com 17,2\%, sendo que, dentre todos os municípios brasileiros, os dois apresentam as maiores especializações setoriais na "Fabricação de artigos de malha", visto que Monte Sião tem mais de $66 \%$ de seus empregados formais da indústria alocados na indústria de malha, e Jacutinga mais de $57 \%$.

\begin{tabular}{|c|l|l||}
\hline VARIÁVEIS & \multicolumn{1}{|c||}{$\begin{array}{c}\text { MONTE } \\
\text { SIÃO/MG }\end{array}$} & $\begin{array}{c}\text { JACUTINGA/ } \\
\text { MG }\end{array}$ \\
\hline $\begin{array}{c}\text { POPULAÇÃO } \\
\text { TOTAL }\end{array}$ & 18.195 & 19.004 \\
\hline $\begin{array}{c}\text { POPULAÇÃO } \\
\text { URBANA }\end{array}$ & $12.729(70 \%)$ & $14.316(75,3 \%)$ \\
\hline $\begin{array}{c}\text { POPULAÇÃO } \\
\text { OCUPADA }\end{array}$ & $10.337(56,8 \%)$ & $9.705(51 \%)$ \\
\hline $\begin{array}{c}\text { DESEMPREGO } \\
\text { (DESOCUPADOS) }\end{array}$ & $235(2,2 \%)$ & $235(2,3 \%)$ \\
\hline $\begin{array}{c}\text { PIB MUNICIPAL } \\
\text { E PIB PER } \\
\text { CAPITA }\end{array}$ & $\mathrm{R} \$ 122.180 .000 /$ & $\mathrm{R} \$ 106.974 .000 /$ \\
$\mathrm{R} \$ 5.624 /$ & $5.507 /$ \\
\hline \hline
\end{tabular}

Tabela 1 - Caracterização demográfica e econômica dos principais municípios do Circuito das Malhas

Fonte: IBGE (2000, 2002 e 2004) e Seade.

A especialização da região na produção de artigos em malha se desenvolveu em um contexto de estagnação da atividade agrícola local que estimulou o renascimento da produção de peças de malha artesanais confeccionadas, em pequenas quantidades, por famílias de origem italiana. Em período de expansão da industrialização no interior do estado de São Paulo e exploração do turismo termal - a partir das décadas de 1960-1970 a manufatura de malhas ganha impulso com a descoberta de um potencial mercado consumidor de artigos semi-artesanais ligado ao movimento turístico regional. Nos anos 70 e 80 essa produção se expande com a aquisição de máquinas têxteis elétricas, levando a um aumento da produtividade da indústria local e estimulando a formação de Associações Empresariais representativas que passam a realizar Feiras periódicas de grande sucesso. Nos anos 90, com investimentos em tecnologia de produção, marketing, acabamento e inovação em modelos, o "Circuito das Malhas" se consolida como uma referência na produção de peças de vestuário no Brasil, considerando o peso do Estado de Minas Gerais $(14,7 \%$ dos estabelecimentos do segmento no país) na indústria de vestuário e têxtil brasileira (BORIN, 2002). 
Desta forma, o conceito de governança, aplicado ao contexto sócio-produtivo do "Circuito das Malhas do Sul de Minas Gerais", traz a possibilidade de se identificar os principais atores que atuam e exercem influência nas dinâmicas econômico-territoriais locais e cujas sinergias e vínculos permitem a construção de instituições e organizações, algumas delas formalizadas e sedimentadas, como as associações comerciais e poder público local (Prefeituras), e outras ainda em estágio latente, baseadas em acordos e convenções tácitas, como é o caso do Circuito Turístico das Malhas. Sem contar a ação das próprias malharias e confecções locais, que são atores primordiais, ao lado do poder público, na definição das formas e estratégias de competitividade territorial local.

Concordamos então com Markusen (2002, p. 58) quando concebe os atores enquanto elementos essenciais no processo decisório no âmbito da geografia econômica, sendo definidos como:

[...] instituições que funcionam como agentes decisórios, empreendedores que definem estabelecer ou criar firmas em determinados locais, trabalhadores que tomam a decisão de migrar, incluindo também entidades de caráter não lucrativo, cooperativas, grupos comunitários, associações profissionais, organizações religiosas, sindicatos trabalhistas e, acima de tudo, o Estado.

A atividade de intermediação que as Associações Comerciais e Indústriais exercem cria facilidades quanto ao acesso a determinados serviços de consultoria, capacitação para o trabalho e logística. Esse papel é bem caracterizado em Monte Sião, onde a entidade é referência em treinamento gerencial para cerca de $35 \%$ das empresas e treinamento de funcionários para mais de $27 \%$. Instituições como SEBRAE (Serviço Nacional de Apoio às Micro e Pequenas Empresas) e SENAI (Serviço Nacional de Aprendizado Industrial parte integrante do Sistema Confederação Nacional da Indústria - CNI - e das Federações das Indústrias dos Estados) aparecem também como relevantes na oferta de assessoria técnica, treinamento gerencial e treinamento da mão-de-obra, geralmente consorciados com as próprias Associações Comerciais e Indústriais e Prefeituras locais.
No município de Jacutinga, por exemplo, mais de $76 \%$ dos estabelecimentos identificaram a Associação Comercial e Industrial local, a ACIJA (Associação Comercial, Industrial e Agropecuária de Jacutinga/MG), como uma instituição importante para a indústria de malhas do município, ou seja, as próprias malharias já fizeram uso de algum tipo de serviço ou vantagem oferecido pela Associação. Em Monte Sião ocorre situação semelhante, com mais de $72 \%$ das malharias indicando a Associação Comercial e Industrial local, ACIMS (Associação Comercial, Industrial e Empresarial de Monte Sião/MG), como a instituição mais atuante no município. Em segundo lugar, em ambos os municípios, aparece o "Circuito das Malhas do Sul de Minas" que, apesar de ainda não desenvolver muitas ações concretas como instituição, já é utilizado como referência pelos produtores locais devido às vantagens de divulgação externa e o referencial de procedência e qualidade de produção que o termo confere à indústria de malhas da região. Em um terceiro patamar, como referência institucional do Circuito das Malhas, estão as prefeituras, muito próximas dos bancos (públicos e privados), a despeito das várias críticas que ambos receberam quanto a investimentos em infra-estrutura e condições de financiamento. Menor parcela mencionou também o apoio do Sebrae e Senai - através de cursos e apoio técnico - geralmente intermediados pelas próprias Associações.

\section{Considerações Finais}

Dentre os elementos apontados por Fuini (2007) como característicos de um perfil dos recursos e ativos territoriais específicos da região do "Circuito das Malhas do Sul de Minas", pelo menos três deles estão diretamente relacionados à temática da "governança territorial":

a) Especialização setorial local e adensamento da cadeia produtiva local dentro dos municípios e entre os municípios permitindo identificar, no tecido sócio-produtivo local, a configuração de um Arranjo Produtivo Local (APL);

b) Arcabouço institucional necessário à inovação e articulação mínimas entre os atores locais e agentes externos, tarefa exer- 
cida, sobretudo, pelas Associações comerciais e industriais através dos serviços que oferecem;

c) Envolvimento de vários municípios no projeto do "Circuito Turístico das Malhas do Sul de Minas", que institucionalizará a procedência da produção regional, distinguindo-a de outras regiões e fortalecendo a integração das cadeias produtivas entre municípios.

Além das especificidades territoriais acima expostas, o "Circuito das Malhas" é detentor também de uma outra vantagem competitiva essencial: a proximidade geográfica em relação aos principais centros consumidores do país (Região Sudeste), apesar da tendência à diversificação estadual e regional das vendas locais.

No entanto, a região possui também alguns gargalos e carências à competitividade e expansão econômica, analisados na condição de recursos e ativos genéricos. Dos elementos que ainda constituem a fragilidade competitiva do "Circuito" pode ser imputada como, por exemplo, a baixa instrução e competência técnica da mão-de-obra, carência de serviços mais sofisticados (crédito, consultorias) e a fragilidade do vínculo cooperativo entre atores privados, poder público municipal e os sindicatos, concomitante ao individualismo empresarial, fatores estes que contrabalanceados em relação aos recursos e ativos específicos, resultam na caracterização da situação de competitividade e desenvolvimento territorial dos municípios centrais da região das malhas do sul-mineiro.

O contexto sócio-produtivo do "Circuito das Malhas do Sul de Minas" passa, no momento atual, por um processo de transição em sua evolução tecnológica e nível de integração sócio-institucional. O atendimento às exigências por inovação tecnológica em termos de utilização de maquinário avançado e adaptação da mão-de-obra parece agora dar lugar à demanda por uma aproximação institucional entre os atores principais do "Circuito", visto que a cooperação poderia funcionar como importante alavanca territorial para o acesso a serviços especializados; estímulo à inovação incremental - sobretudo no período de outono-inverno; desenvolvimento de projetos turísticos e busca por novos mercados consumidores, via- bilização de melhores condições de trabalho e de qualificação da mão-de-obra e, aumento no número de empresas que exportam seus produtos e que acessam mercados mais sofisticados.

Tais mudanças permitiriam à região dar um salto qualitativo importante rumo à criação e à consolidação de novos "recursos e ativos" específicos tão importantes na busca por uma competitividade territorial crescente. Neste sentido, maior parte dessas transformações passa necessariamente pela articulação de novas formas de governança entre os atores territoriais, permitindo construir articulações inéditas entre as empresas, o poder público, em seus diversos níveis, e os demais atores e instituições locais. Esta maior integração deveria atender às expectativas coletivas de se buscar a especificação crescente dos recursos territoriais locais, associado a um projeto mais amplo de desenvolvimento territorial, visto que este termo designa:

[...] uma ação coletiva intencional de caráter local - um modo de regulação territorial associado a uma cultura, a um plano e instituições locais. É dinamizado por expectativas de vantagens locacionais, no qual o território é considerado um recurso específico e um ator principal do desenvolvimento econômico regional, a um só tempo disponível e a ser criado. Por último, trata-se de um processo de mudança social, de caráter qualitativo e endógeno, capaz de produzir solidariedade, cidadania comunitária e bem-estar para a população de uma dada localidade e região". (PIRES; MULLER; VERDI, 2007, p. 439).

\section{Referências}

BENKO, G. Economia, espaço e globalização: Na aurora do século XXI. São Paulo: Hucitec, 1996.

BENKO, G.; PECQUEUR, B. Os recursos de territórios e os territórios de recursos. Geosul. Florianópolis, v. 16, n. 32, p. 31-50, jul./dez, 2001.

BOYER, R. A Teoria da Regulação: Uma Análise crítica. São Paulo: Nobel, 1990.

BORIN, P. Divisão interurbana do trabalho e uso do território nos municípios de Águas de Lindóia (SP), Lindóia (SP), Serra Negra (SP), Socorro (SP) e Monte Sião (MG). $128 \mathrm{f}$. Dissertação (Mestrado em Geografia) - USP, São Paulo, 2003.

CASTRO, I. E. de. Instituições e Território: Possibilidades e limites ao exercício da cidadania. Geosul. Florianópolis, v. 18, n. 36, p. 7-28, 2003. 
COLLETIS-WAHL, K.; PECQUEUR, B. Territories, Development, and Specific Resources: What Analytical Framework?. Regional Studies. Reino Unido, v. 35, n. 5, p.449-59, 2002.

FUINI, L. L. A relação entre competitividade e território no Circuito das Malhas do Sul de Minas. Dissertação (Mestrado em Geografia) - Programa de Pós-graduação em Geografia, IGCE-UNESP, Rio Claro, 2007.

HUMPHREY, J.; SCHIMITZ, H. How Does Insertion in Global Value Chains Affect Upgrading in Industrial Clusters?. Regional Studies. Reino Unido, v. 36, n. 9, p. 1017-27, 2002.

MARKUSEN, A. Mudança econômica regional segundo o enfoque centrado no ator. In DINIZ, C. C.; LEMOS, M. B. (org.). Economia e território. Belo Horizonte: Ed. UFMG, 2005.

PIRES, É. L. S. Os mercados de trabalho nas Zonas de Integração Regional: A construção inacabada da regulação salarial na União Européia. Tese (Livre Docência) IGCE, UNESP, Rio Claro, 2003.

PIRES, É. L.; MULLER, G.; VERDI, A. R. Instituições, Territórios e Desenvolvimento Local: Delineamento preliminar de aspectos teóricos e morfológicos. Geografia - Associação de Geografia Teorética. Rio Claro/SP, v. 31, p. 437-54, set/dez. de 2006.

PORTER, M. Competição: Estratégias Competitivas Essenciais. Rio de Janeiro: Elsevier/Campus, 1999.
SANTOS, M. A Natureza do Espaço: Técnica e Tempo, Razão e Emoção. São Paulo: Hucitec, 1996.

SENGENBERGER, W.; PIKE, F. Distritos Industriais e Recuperação Econômica Local: Questões de pesquisa e de política. In: COCCO, G., et al. (org.). Empresários e empregos nos novos territórios produtivos: $\mathrm{O}$ caso da Terceira Itália, 2. ed. Rio de Janeiro: Coleção Espaços do Desenvolvimento, Sebrae e DP\&A Editora, 2002, p. 101-46.

STORPER, M.; HARRISON, B. Flexibilidade, Hierarquia e Desenvolvimento Regional: As mudanças de estrutura dos Sistemas Produtivos Industriais e seus novos modos de Governância nos anos 90. In: BENKO, G. e LIPIETZ, A (org.), As Regiões Ganhadoras. Distritos e Redes: Os novos paradigmas da Geografia Econômica. Oeiras: Celta Editora, 1994, p. 171-88.

STORPER, M. Desenvolvimento territorial na economia global do aprendizado: o desafio dos Países em Desenvolvimento. In: RIBEIRO, L. C. de Q.; SANTOS JR. O. A. dos (org.). Globalização, fragmentação e reforma urbana: O Futuro das Cidades Brasileiras na Crise. São Paulo: Civilização Brasileira, 1995, p. 23-63.

VALENTIM R. O Capital Social como um dos elementos que compõem a Dinâmica do Desenvolvimento Regional. In: BECKER, D. F.; WITTMAN, M. L. (org.). Desenvolvimento regional: abordagens interdisplinares. Sta. Cruz do Sul/RS: Edunisc, 2003, p.245-61. 